\title{
ENTREVISTA COM A PROFESSORA ROMENA CORINA NUTU ACERCA DAS OBRAS DE FERINANDO PESSOA E DO ENSINO DE LINGUA E LITERATURA PORTUGUESAS NA ROMENIA
}

http://dx.doi.org/10.11606/issn.2175-3180.v13i24p257-263*

Por Eduardo Neves da Silva ${ }^{\mathrm{I}}$

Corina Nutu, 28 anos, é professora assistente de língua e literatura portuguesas da Faculdade de Línguas e Literaturas Estrangeiras da Universidade de Bucareste, Romênia. No início de 2015, doutorou-se com um estudo intitulado Sinceridade e teatralidade nos sonetos ingleses de Fernando Pessoa, tendo desenvolvido parte de sua pesquisa no Centre de Recherches Interdisciplinaires sur les Mondes Ibériques Contemporains (CRIMIC), da Université Paris-Sorbonne (Paris IV). Entre pesquisas e participação em eventos no exterior, Corina Nutu divide suas atividades acadêmicas com o seu trabalho de tradutora. Já traduziu do português para o romeno os dez livros que compõem a série "O Bairro", de Gonçalo M. Tavares, publicados na Romênia em dois volumes. Também traduziu, em colaboração, o livro Fernando Pessoa: uma quase autobiografia, de José Paulo

\footnotetext{
* Publicada originalmente na revista Desassossego, v. 7, n. 14, dez/2015:

https://www.revistas.usp.br/desassossego/issue/view/8410

DOI original: http://dx.doi.org/10.11606/issn.2175-3180.v7i14p158-163

I Universidade de São Paulo, São Paulo, Brasil.
} 
Cavalcanti Filho. Além destas publicações, estão no prelo as traduções para o romeno do livro De todo lo visible y lo invisible, da escritora espanhola Lucía Etxebarria, e de Helena, de Machado de Assis.

EDUARDO NEVES DA SILVA: Você concluiu recentemente seu doutorado com um estudo sobre os sonetos em inglês de Fernando Pessoa. Qual foi exatamente o tema de sua pesquisa?

CORINA NUTU: Na minha tese examinei o conjunto de sonetos shakespearianos de Pessoa, 35 Sonnets, posto em relação com as ideias e visto como uma procura duma alternativa à lírica romântico-simbolista e duma solução para aquilo que Pessoa considera ser uma crise da linguagem.

ENS: Há ainda muito a ser descoberto na obra de Fernando Pessoa? Digo, por mais que sua poesia tenha sido exaustivamente estudada na academia, existe algo na obra de Pessoa que a crítica especializada tenha negligenciado de alguma forma?

$C N$ : Visto que muitos dos manuscritos deixados por Pessoa na sua famosa arca ainda não foram decifrados e publicados, por agora não se pode falar dum conhecimento exaustivo da sua obra. Ademais, nem todas as obras publicadas receberam a mesma atenção por parte da crítica; os sonetos ingleses, por exemplo, foram relativamente menos explorados do que a poesia portuguesa. Por outro lado, é certo que se escreveu muitíssimo sobre este poeta e que, desde a publicação dos influentes estudos de João Gaspar Simões e Jacinto do Prado Coelho, algumas ideias sobre a poesia de Pessoa foram repetidas exaustivamente. Não me parece, no entanto, que a imagem trágica e irremediavelmente pessimista de Pessoa, perpetuada durante tanto tempo pela crítica, seja completa e definitiva, ou reflita a sutileza, o espírito lúdico e a riqueza da sua obra. Para poder dizer algo de novo sobre Pessoa é necessário, antes de tudo, questionar os lugares comuns da exegese pessoana.

ENS: Bernardo Soares, um dos heterônimos de Fernando Pessoa, afirma que "minha pátria é a língua portuguesa". Você acredita que, pelo fato de esses sonetos serem escritos em língua inglesa, eles se configurem como 
uma voz poética tão característica e singular quanto a de um novo heterônimo?

CN: Na minha opinião, nos 35 Sonnets o uso do inglês (ou, mais precisamente, o intento de emular o inglês isabelino e a complexidade formal dos sonetos shakespearianos) não implica tanto a configuração duma nova voz poética heteronímica, quanto uma reinvenção da figura de Shakespeare, que acaba por refletir as preocupações tipicamente modernistas e as ideias estéticas de Pessoa ortônimo. Trata-se, ao mesmo tempo, dum distanciamento da poesia romântico-simbolista portuguesa, no intuito de criar uma nova linguagem poética a partir dum modelo que pertence a outra época e a outro espaço cultural. Embora esta procura não seja completamente bem-sucedida (de fato, nos últimos poemas do conjunto o próprio eu lírico mostra-se consciente da sua falha), nos sonetos entrevêse a possibilidade duma solução para a crise: a redescoberta do potencial criador do discurso e da ficção, que será, mais tarde, um dos fundamentos do projeto heteronímico de Pessoa.

ENS: No curso de Letras da Universidade de São Paulo, os alunos cumprem o ciclo básico no primeiro ano. No segundo ano, conforme a média de notas semestrais do ciclo básico, os alunos escolhem ou a habilitação em língua portuguesa e/ou uma ou mais línguas estrangeiras, ou apenas em linguística. Como é estruturado o curso de Letras na Universidade deBucareste?

CN: Na Faculdade de Línguas e Literaturas Estrangeiras e na Faculdade de Letras da Universidade de Bucareste, o primeiro ciclo consiste numa licenciatura de três anos, que pode ser completada com um mestrado de dois anos e, depois, com o doutoramento. Os alunos de licenciatura escolhem desde o início uma habilitação, que consiste, tipicamente, em duas línguas estrangeiras no caso da Faculdade de Línguas e Literaturas Estrangeiras, ou em romeno e uma língua estrangeira no caso da Faculdade de Letras. 
ENS: Quais disciplinas você leciona na Universidade de Bucareste? De modo geral, como tem sido a procura pelo curso de língua portuguesa por parte dos alunos de Letras?

CN: Dou aulas de Prática da língua portuguesa e de Literatura e cultura portuguesa aos alunos de licenciatura da Faculdade de Línguase Literaturas Estrangeiras e da Faculdade de Letras. Há bastante procura para a língua portuguesa; atualmente, temos por volta de oitenta alunos do primeiro ano que escolheram estudar português.

ENS: Há cursos universitários de português em outras universidades da Romênia? Se sim, em quais universidades?

CN: Que eu saiba, atualmente há um curso de português na Universidade Ovidius, de Constanţa, e aulas de português para principiantes na Universidade Babeş-Bolyai, de Cluj, na Universidade de Oeste de Timişoara e na Universidade Romeno-Americana de Bucareste.

ENS: A Universidade de Bucareste promove algum evento sobre literatura portuguesa? Se sim, qual é e em que época do ano ocorre?

$C N$ : Não há um evento anual dedicado exclusivamente à literatura portuguesa, mas a Associação dos Estudantes da Faculdade de Línguas e Literaturas Estrangeiras organiza todos os anos, em abril, a Noite Cultural Ibérica, que é uma ocasião para os alunos entrarem em contato com as culturas espanhola e portuguesa através de jogos, atividades práticas, projeções de filmes, etc. Para além disso, a Secção de Português [do Departamento de Linguística Românica, Línguas e Literaturas Iberoromânicas e Italiano] organiza regularmente colóquios, jornadas de estudos ou palestras com temas relacionados tanto à língua, como à literatura portuguesa.

ENS: No Brasil, os programas de pós-graduação stricto sensu das humanidades enfrentam, além da escassez de recursos, a pressão, por parte das agências de fomento e avaliação, no sentido de aumentarem sua produção científica (artigos, organização de eventos, etc.), com base no produtivismo das áreas de exatas e biológicas. Em relação à pós-graduação 
na Romênia, quais têm sido os principais desafios e problemas da área de humanidades, em especial da área de Letras?

CN: Na Romênia, o controle das agências de avaliação não é tão estrito como no Brasil, mas a falta dos recursos é um problema igualmente grave, sobretudo na área das humanidades. Obter financiamento para organizar colóquios ou outros eventos é bastante difícil e as bolsas oferecidas pelas fundações romenas são atribuídas em primeiro lugar aos pesquisadores da área das ciências exatas e menos aos humanistas, que muitas vezes têm de solicitar o apoio de instituições culturais estrangeiras. $\mathrm{Na}$ área das línguas e literaturas estrangeiras, sobretudo quando o tema da pesquisa é relacionado a uma língua ou cultura menos conhecida e estudada na Romênia, é quase impossível ter acesso à bibliografia necessária para realizar uma tese de doutoramento sem apoio financeiro ou bolsas de investigação no estrangeiro.

ENS: Embora tanto a língua portuguesa quanto a língua romena tenham origem latina, há grandes diferenças entre ambas. Em seu trabalho como tradutora, quais têm sido as maiores dificuldades em verter uma obra literária do português para o romeno?

CN: Um problema bastante grave é o fato de que os dicionários portugueses-romenos publicados até agora na Romênia não são suficientemente abrangentes para facilitarem o trabalho dos tradutores literários, mas esta falta pode ser compensada através do uso dos dicionários monolíngues e dos recursos online. Por outro lado, quando traduzi a série "O Bairro", de Gonçalo M. Tavares, o maior desafio foi preservar o humor do texto português e adaptá-lo aos recursos da língua romena. Não é fácil transpor para outra língua trocadilhos e raciocínios fundamentados em certas particularidades linguísticas do português, tentando produzir efeitos cômicos equivalentes sem trair o espírito do original. Felizmente, a distância entre o romeno e o português não é tão grande que torne esta tarefa impossível. 
ENS: Como você avalia as trocas culturais (as literárias, em especial) entre Portugal e a Romênia nos últimos anos? Há alguma assimetria nessa relação?

CN: Os romenos vão-se familiarizando com a literatura portuguesa. Nos últimos anos várias editoras romenas têm publicado traduções de obras de autores como Fernando Pessoa, José Saramago, António Lobo Antunes, José Luís Peixoto, Gonçalo M. Tavares ou Rui Zink. Houve, também, visitas de escritores portugueses à Romênia: a de Rui Zink, que participou em setembro do lançamento da versão romena do romance $A$ instalação do medo, é a mais recente. Embora a presença dos autores romenos em Portugal tenha sido menos visível, a partir de 2005, quando o Instituto Cultural Romeno iniciou o primeiro dos seus programas de apoio à tradução, os leitores portugueses entraram em contato com as obras de escritores romenos contemporâneos como Mircea Cărtărescu, Ana Blandiana ou Gabriela Adameşteanu. Acho que já foram criadas as bases para estabelecer trocas culturais mais consistentes.

ENS: Que grande escritor (a) romeno (a) os portugueses e os brasileiros precisam descobrir? E qual grande escritor (a) brasileiro (a) e/ou português (a) o público romeno ainda não descobriu?

CN: Vou mencionar um autor romeno do período entre guerras, cujos livros já começaram a ser traduzidos no Brasil, mas que não sei se é familiar à maioria dos leitores brasileiros: Max Blecher, cujo romance Intâmplări din irealitatea imediată (Acontecimentos da irrealidade imediata) foi publicado em 2013 pela editora Cosac \& Naify, na tradução de Fernando Klabin. Tratase dum autor não muito conhecido, nem sequer pelos romenos, mas cuja obra atípica, comparada por Eugen Ionescu à de Kafka, vale a pena descobrir. No que diz respeito à literatura brasileira, as traduções para romeno dos livros A paixão segundo G. H. e Perto do coração selvagem de Clarice Lispector foram publicadas recentemente (a primeira em 2014 e a segunda em 2015, pela editora Univers, na tradução de Dan Munteanu Colán), e alegra-me muito que os romenos possam finalmente conhecer esta escritora. O meu sonho, no entanto, é ver os contos de Clarice (sobretudo Laços de família) traduzidos para romeno, e espero que se realize algum dia. Também gostaria que os romenos pudessem ler os livros de alguns 
escritores portugueses contemporâneos que até agora não foram traduzidos; Mário de Carvalho é um deles. Em suma, ainda há muitos autores e livros por descobrir, mas já demos os primeiros passos, e isso parece-me importantíssimo.

Licença: (우 (1) ()

Concepção e realização da entrevista:

Eduardo Neves da Silva

Doutor egresso do Programa de Pós-Graduação em Literatura Portuguesa da Universidade de São Paulo.

Contato: edu nsp@hotmail.com 